de $50 \mathrm{~Hz}$ em short pulse tendo a energia sido entregue através de fibra ótica de $320 \mu \mathrm{m}$. Intra e pós-operatório sem complicações tendo apenas referido desconforto local ao $3 .^{\circ}$ dia, sem dor. Após duas semanas mucosa totalmente cicatrizada. Follow-up de 3 anos sem recidiva da lesão ou outras alterações. Discussão e conclusões: A fotocoagulação de hemangiomas da região oral e perioral com LASER Nd:YAG é um tratamento seguro, rápido e com poucas complicações. O baixo risco de hemorragia permite que a técnica seja aplicada em clínicas não equipadas para cirurgia e oferece importantes vantagens para o operador e paciente. A principal indicação são as lesões que causem desconforto estético ou funcional, nas quais é clara a natureza benigna da lesão.

http://doi.org/10.24873/j.rpemd.2022.01.896

\section{\#039 Osteosclerose idiopática num paciente jovem - A propósito de um caso clínico}

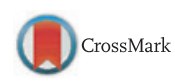

Inês Ferreira*, Irene Pina-Vaz

Faculdade de Medicina Universidade do Porto, CINTESIS

Introdução: A osteosclerose idiopática é uma lesão radiopaca localizada, assintomática, não expansível, de etiologia desconhecida. Está frequentemente associada à mandíbula, na região periapical do primeiro molar inferior, seguida do primeiro e segundo pré-molares inferiores. Geralmente surge no final da primeira ou início da segunda década de vida. Radiograficamente caracteriza-se por uma lesão óssea hiperdensa bem definida, manifestando-se como uma massa redonda, elíptica ou irregular. Descrição do caso clínico: Paciente sexo feminino, caucasiana, de 10 anos de idade, compareceu para uma consulta de Medicina Dentária de rotina. A história médica não revelou qualquer patologia sistémica associada. No exame físico intra-oral não foram observadas alterações relevantes. No exame radiográfico foi registada uma lesão radiopaca localizada na região periapical do dente 46 , com um ligeiro aumento do espaço correspondente ao ligamento periodontal das raízes mesiais, apicalmente, e integridade da lâmina dura. A resposta aos testes térmicos foi positiva, percussão negativa e profundidade de sondagem normal. Após exame clínico e radiográfico detalhado foi diagnosticada osteosclerose idiopática no dente 46. Após follow-up de 3 anos, a paciente mantém-se estável com ausência de sinais/sintomas, sem alteração radiográfica relevante. Discussão e conclusões: Casos clínicos com presença de alterações radiográficas perirradiculares, sem aparente etiologia endodôntica devem ser alvo de um exame clínico e radiográfico particularmente detalhado. Apesar de a sua prevalência estar geralmente associada a uma determinada faixa etária, raça ou outras especificidades, a sua possibilidade não deve ser descartada num diagnóstico diferencial adequado. No presente caso, apresentaram-se como possíveis patologias a diferenciar: osteíte condensante, displasia óssea focal, cementoblastoma e osteoma. Tendo-se diagnosticado osteosclerose idiopática no dente 46 nenhum tratamento foi indicado, além de um controlo periódico, pois há pouca ou nenhuma tendência de progressão ou alteração destas lesões. A realização de biópsia deve ser considerada apenas se ocorrerem sintomas ou expansão da cortical óssea. O diagnóstico diferencial deste tipo de lesões pode representar um desafio para o médico dentista, em particular em pacientes jovens. Erros no diagnóstico podem conduzir à realização de procedimentos invasivos, acarretando riscos desnecessários.

http://doi.org/10.24873/j.rpemd.2022.01.897

\#040 Parotidite bacteriana aguda em contexto de síndrome de Sjögren: Caso clínico

Ana Melissa Marques, Maria Inês Borges, Simão Nogueira, Maria Fernanda Costa *, José Pedro Figueiredo

Serviço de Estomatologia - Centro Hospitalar e Universitário de Coimbra

Introdução: A parotidite bacteriana aguda é causada em cerca de 80 \% dos casos por Staphylococcus aureus, seguida de outras bactérias coco Gram-positivas, bacilos Gram-negativos e anaeróbios. As espécies Streptococcus são bactérias Gram-positivas, comensais na cavidade oral, incluindo a subespécie salivarius. Por sua vez, a Citrobacter freundii é uma bactéria anaeróbia Gram-negativa da família Enterobacteriaceae, encontrada no meio ambiente, cuja infeção pode estar associada ao consumo de água contaminada por hospedeiros imunocomprometidos. A parotidite pode ocorrer por múltiplas condições que favorecem a colonização bacteriana, como diminuição do fluxo salivar, obstrução ductal, desidratação e imunossupressão. Apresenta-se como uma tumefação na região parotídea dolorosa. À palpação, pode ser detetado o endurecimento localizado, por vezes, com saída de conteúdo purulento pelo ducto de Stenon. O tratamento assenta na terapêutica antibiótica e na hidratação oral. A antibioterapia, inicialmente empírica, deve ser ajustada posteriormente, assim que for obtido o resultado do exame cultural. Descrição do caso clínico: Mulher, 74 anos, com história de síndrome de Sjögren, recorre ao serviço de urgência por dor e tumefação da região parotídea bilateralmente, com 3 dias de evolução. Apresentava dor e drenagem bilateral de conteúdo purulento à palpação da região parotídea. Sem outras alterações. Foi realizado o estudo por ecografia, que negou a presença de coleções purulentas e de cálculos intraductais, tendo revelado alterações do parênquima compatíveis com a doença de base. A doente foi medicada com clindamicina e procedeu-se à colheita do exsudato purulento, com exame cultural positivo para as bactérias Citrobacter freundii e Streptococcus salivarius, ambas sensíveis à medicação em curso, pelo que se manteve a antibioterapia durante 10 dias. A senhora apresenta-se sem queixas e com resolução total do quadro clínico. Discussão e conclusões: A microbiota oral contém centenas de espécies bacterianas, com predomínio de bactérias anaeróbias, que em condições de desequilíbrio, podem tornar-se patogénicas. A síndrome de Sjögren é uma patologia autoimune que afeta as glândulas salivares, caracterizando-se por queixas de xerostomia. A diminuição do fluxo salivar leva a um decréscimo da 'clearance' bacteriana, permitindo 
a colonização de agentes patogénicos pelo ducto parotídeo, o que predispõe ao desenvolvimento de parotidite supurativa. http://doi.org/10.24873/j.rpemd.2022.01.898

\section{\#041 Granulomatose orofacial: Um diagnóstico de exclusão

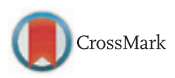

Maria Inês Borges*, Ana Melissa Marques, Beatriz Dominguez, Simão Nogueira, Fátima Carvalho, José Pedro Figueiredo

Serviço de Estomatologia - Centro Hospitalar e Universitário de Coimbra

Introdução: A granulomatose orofacial (GOF) é uma inflamação granulomatosa, não específica, dos tecidos orofaciais, sem doença sistémica associada. É uma condição rara, idiopática e mais frequente em adultos jovens. Caracteriza-se por edema orofacial recorrente ou persistente; em $90 \%$ dos casos envolve o lábio. Pode afectar toda a cavidade oral, sendo as manifestações mais frequentes: edema, úlcera ou pápulas. O envolvimento isolado do lábio é designado queilite granulomatosa/de Miescher. Se associada a paralisia facial e língua fissura é designada Síndrome Melkerson-Rosenthal. O diagnóstico é feito com biópsia da lesão e demonstração de inflamação granulomatosa no estudo histológico. Por se tratar de um diagnóstico de exclusão, devem ser eliminadas outras causas de inflamação granulomatosa, como alergénios, corpo estranho, sarcoidose, doença de Crohn ou tuberculose. A primeira linha de tratamento é corticoterapia (tópica, intra-lesional ou sistémica). Descrição do caso clínico: Doente do sexo masculino, 17 anos, referenciado à consulta de Estomatologia por edema persistente do lábio inferior, com 6 meses de evolução. Referia queixas de dor abdominal, diarreia/obstipação e ligeira perda ponderal. Negou anorexia, febre, hipersudorese ou queixas respiratórias. Ao exame objectivo, apresentava edema do lábio inferior à esquerda, não doloroso e não infiltrativo. Apresentava hiperemia gengival. Sem dismetrias faciais, sem desvio das comissuras, com pregas faciais mantidas. ENS sem alterações. Foi realizada biópsia da lesão, cujo estudo identificou um processo inflamatório granulomatoso. O estudo diagnóstico incluiu o doseamento da ECA, serologia para Micobacterium tuberculosis e realização de endoscopia e colonoscopia, com biópsias seriadas. Os resultados foram negativos. Após exclusão de sarcoidose, tuberculose e doença de Crohn, assumiu-se o diagnóstico de GOF. O tratamento incluiu corticoterapia, reforço da higiene oral e aplicação tópica de clorexidina nas gengivas, com melhoria do edema do lábio e hiperemia gengival. Discussão e conclusões: A GOF é um diagnóstico de exclusão; a realização de uma história clínica, exame objectivo e estudo diagnóstico detalhados permite a eliminação de outras causas de inflamação granulomatosa. O diagnóstico precoce e tratamento podem prevenir deformidades permanentes da cavidade oral. A remissão espontânea da doença é improvável e os doentes podem desenvolver novos sintomas, sendo importante o seguimento regular, a longo prazo.

http://doi.org/10.24873/j.rpemd.2022.01.899
\#042 Disfagia grave por Sarcoma de Kaposi oral

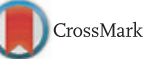

Rui Seixas*, Natacha Ribeiro, Manuel Tolentino, Dinora Martins, Carlos Matos

Serviço de Estomatologia - Centro Hospitalar de Setúbal, Hospital São Bernardo

Introdução: O Sarcoma de Kaposi (SK) é a principal neoplasia maligna na infecção pelo Vírus da Imunodeficiência Humana (VIH). Hoje em dia, a sua apresentação clínica é incomum, pela introdução da terapêutica anti-retroviral. Dos doentes com SK é estimado que cerca $70 \%$ apresentem manifestações orais, muitas delas com grande impacto clínico no aparelho estomatognático. Descrição do caso clínico: Doente do sexo masculino, 43 anos de idade, caucasiano foi referenciado à consulta de Estomatologia por lesão ulcerada na mandíbula à esquerda, com odor fétido e dor, com comprometimento da ingestão de sólidos e líquidos. Como antecedentes pessoais identifica-se infeção por VIH diagnosticada há 14 anos não sendo cumpridor da terapêutica anti-retroviral há 7 anos. Ao exame estomatológico identificou-se no uma lesão exofítica de $7 \mathrm{~cm}$ de maior diâmetro de consistência elástica, coloração vermelho-acastanhada, no $3 .^{\circ}$ quadrante, justa dente 3.3, associado a exsudado purulento abundante. Adicionalmente observou-se várias outras lesões idênticas, de menor diâmetro, no $1 .^{\circ}$ e $2 .^{\circ}$ quadrante e palato. A TC maxilo-facial descreve massa de partes moles da hemiface esquerda com crescimento na face bucal da cavidade oral e adjacente ao rebordo alveolar da mandibula esquerda, com associados sinais de erosão óssea. Realizou-se biópsia incisional das várias lesões cuja análise histopatológica revelou SK com ulceração. Da restante avaliação médica, a TC torácica evidenciou achados compatíveis com SK pulmonar e a avaliação analítica mostrou CD4 143 células/mcL (7\%) e CVVIH-1 5600 cópias/mL (log10 4,75). O tratamento em regime de internamento consistiu em piperacilina-tazobactam e quimioterapia com doxorrubicina associada a radioterapia para citoredução, verificando-se uma melhoria clínica significativa com redução das dimensões da massa oral. Discussão e conclusões: O SK pode acometer qualquer mucosa, mas o seu desenvolvimento na cavidade oral pode causar lesão nos tecidos locais, dor, interferência no uso de prótese ou nas funções oromaxilares. Neste caso, a disfagia grave teve repercussões negativas no estado nutricional, na adesão à terapêutica e na qualidade de vida do doente. O SK oral precisa ser diferenciado clinicamente de outras entidades, como o granuloma piogénico, o hemangioma ou a angiomatose bacilar, e por isso, lesões orais sugestivas devem ser biopsiadas e pacientes com SK diagnosticado por biópsia devem ser testados para VIH. http://doi.org/10.24873/j.rpemd.2022.01.900

\#043 Reabsorção idiopática do côndilo mandibular - A propósito de um caso clínico

Helena Salgado, Bruno Martins*, Josefa Ortiz, Patrícia Fonseca Universidade Católica Portuguesa FMD

Introdução: A reabsorção do côndilo mandibular está relacionada com o aumento anormal de carga sobre a articulação temporomandibular com consequente reabsorção óssea. Isto 